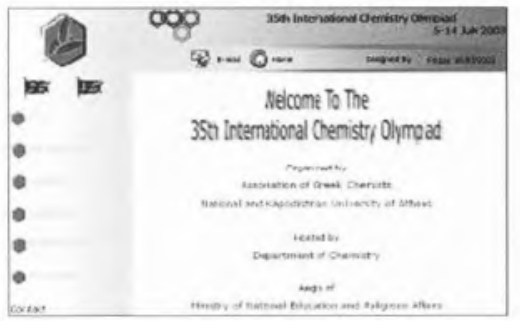

\section{5th International Chemistry Olympiad}

http://www.35icho.uoa.gr

Organizada pela EEX, congénere grega da Sociedade Portuguesa de Química irá decorrer em Atenas a 35. ${ }^{\text {a }}$ edição das Olimpíadas Internacionais de Química. Nesta página, ainda num estado algo incipiente, é possivel encontrar algumas informações úteis sobre esse evento, como notícias, horários para alunos e professores e informações locais. Contém ainda ligações para outros sites relacionados, nomeadamente para o site oficial das Olimpíadas (www.icho.sk), onde é possivel encontrar um breve historial desta organização, regulamentos e uma lista de ligações para os sites de algumas edições anteriores.

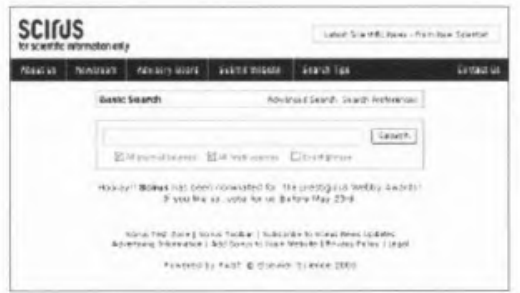

\section{Scirus}

www.scirus.com

Scirus é um motor de pesquisa direccionado apenas para a informação científica. Com uma interface muito simples, a lembrar a do Google, permite procurar artigos cientificos, livros, patentes, conferências ou inclusivamente ficheiros em diversos formatos como, por exemplo, PDF. A pesquisa é facilmente configurável e os resultados podem ser igualmente organizados de acordo com regras definidas pelo utilizador. Numa altura em o número de páginas na In- ternet continua a crescer a ritmo elevado, motores de pesquisa especializados como o Scirus serão cada vez mais uma solução a considerar.

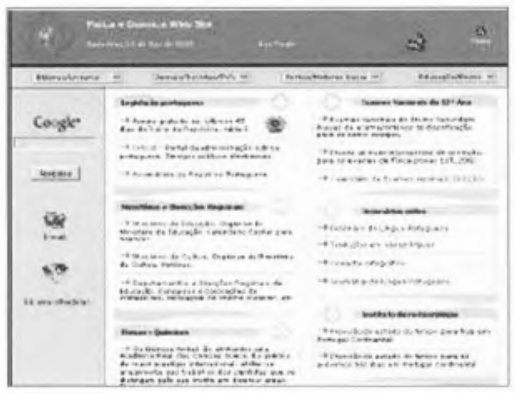

Física e Química Web Site

luisperna.com.sapo.pt

Com uma interface muito agradável, este site apresenta informação variada, e frequentemente actualizada, de interesse para alunos e professores de Fisica e Química. Criado por Luís Perna, professor na Escola Secundária Raul Proença, Caldas da Rainha, encontra-se organizado em diversas secções, podendo encontrar-se tópicos como biografias de cientistas eméritos, glossários, utilitários diversos, software, visualização de moléculas em 3D e experiências de laboratório. Para além destas, apresenta ainda secções como notícias, legislação, exames nacionais do ensino secundário, dicionários, ligações para ministérios e outras mais ligeiras como, por exemplo, passatempos. A mistura criteriosa das diversas temáticas resulta num site muito bem conseguido e de navegação muito fácil.

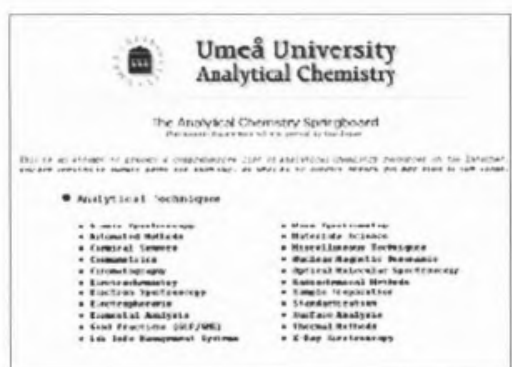

The Analytical Chemistry Springboard www.anachem.umu.se/jumpstation.htm
Localizado no Departamento de Química da Universidade de Umea, Suécia, este site contém uma colecção, muito bem organizada, de endereços especialmente dirigidos para pessoas que trabalham na área de Química Analítica. Divide-se em várias secções como Espectroscopia, Cromatografia, Ressonância Magnética Nuclear, Materiais, Preparação de Amostras e muitas outras. Cada endereço apresentado é acompanhado por uma breve descrição do conteúdo bem assim como ícones que fornecem informação visual sobre o site. 0 autor apresenta ainda uma outra lista de endereços para recursos relacionados. A reter é a ligação para uma outra página, bastante interessante, criada pelo mesmo autor e mantida na mesma Universidade, dirigida a professores (www.anachem.umu.se/eks/pointers.htm) cuja visita também se recomenda.

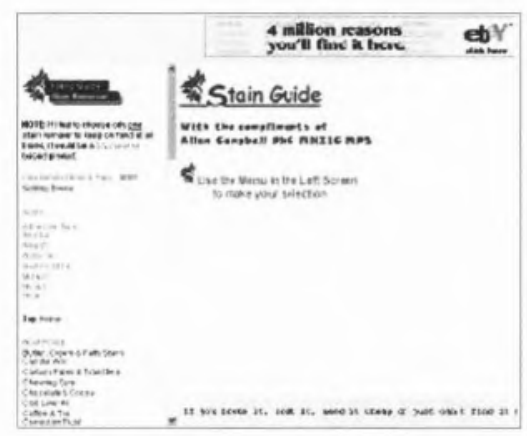

\section{Stain Removal Guide}

www.chemistry.co.nz/stain_frame.htm

Um dos aspectos mais interessantes da Química é a sua presença até nas coisas mais triviais do dia-a-dia. E não há quem não se tenha já confrontado com uma arreliadora nódoa. Para nos ajudar nesta batalha, Allan Campbell compilou uma vasta quantidade de métodos de remoção de diferentes tipos de nódoas em tecidos - de tinta de esferográfica a vinho, de gordura a chocolate, passando por muitas mais. Em todos eles é possivel ver a Química a funcionar. Neste guia são ainda fornecidos conseIhos úteis sobre tratamento de tecidos e endereços de outros sites relacionados com a mesma temática. 


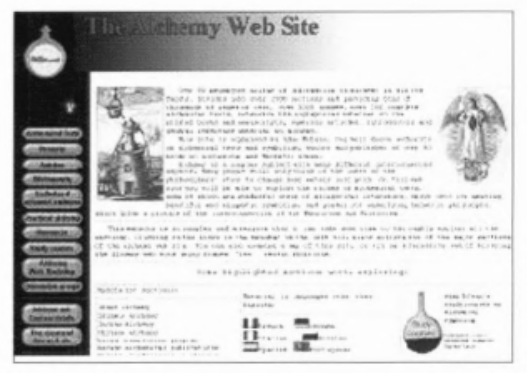

The Alchemy Web Site levity.com/alchemy/
A Alquimia pode ser vista, não apenas etimologicamente, como percursora da Química. Apesar dos alquimistas serem muitas vezes referidos como charlatães e apenas interessados em tentar transformar metais comuns em ouro, o autor deste site, Adam McLean, apresenta-nos a Alquimia como uma ciência complexa e multifacetada virada também para aspectos metafísicos. Para isso, construiu um impressionante arquivo de milhares de documentos que podem ser consultados neste local. A imagística e o simbolismo sempre foram facetas importantes da Alquimia e isso também aqui pode ser verificado tornando o site visualmente muito apelativo.

Jorge Marques Gonçalves jgoncalv@fc.up.pt

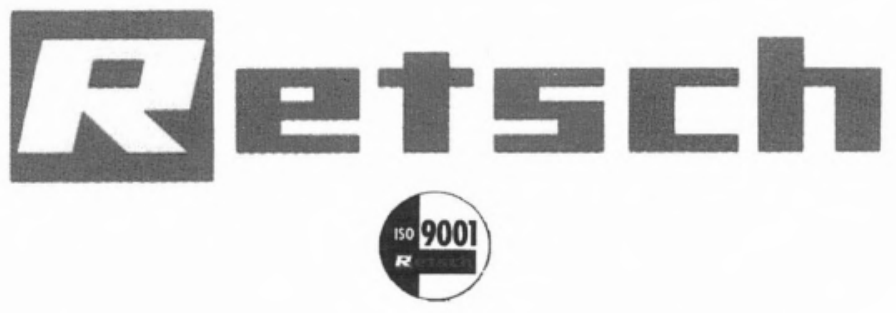

Moinhos

Agitadores de peneiros/peneiros
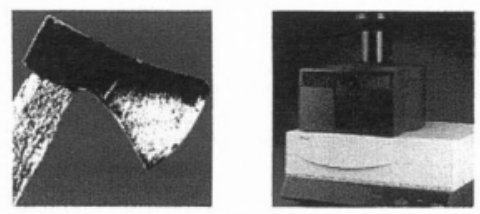

Divisores de amostras
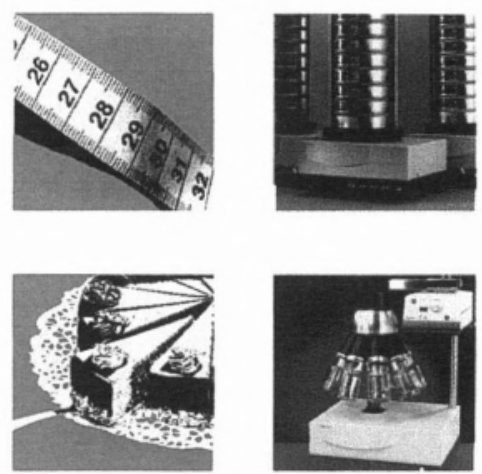

Análise granulométrica automática CAMSIZER / Crystalsizer

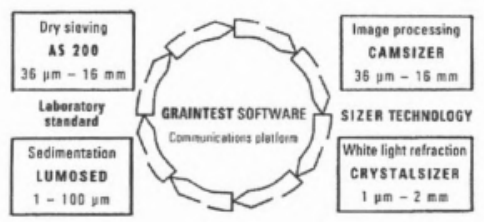

Peça-nos o contacto do agente mais próximo, através dos telefones:

21-352 7293

LISBOA
22-618 4232

O Ompartadar Exclusiva 